\title{
Aproximación Metodológica a los Itinerarios no Motorizados de Mayor Potencialidad para la Intermodalidad "Tren+Bici" en Andalucía
}

\author{
A Methodological Approach to Non-Motorized Itineraries with Greater \\ Potentiality for the "Train+Bike" Intermodality in Andalusia \\ Isabel Aránzazu García-Bello \\ jargarbel@alum.us.es @ https://orcid.org/0000-0001-9239-4331 \\ Universidad de Sevilla, SigTam Consultores. C/ Gonzalo Bilbao 33, bajo 241003 Sevilla
}

Jesús Ventura-Fernández

jventura@us.es $\bigcirc$ https://orcid.org/0000-0002-8271-1011

Universidad de Sevilla. Dpto. de Geografía Física y Análisis Geográfico Regional.

C/ María de Padilla s/n. 41004 Sevilla

\section{INFO ARTÍCULO}

Recibido: 27/5/2019

Revisado: 28/6/2019

Aceptado: 29/6/2019

\section{PALABRAS CLAVE}

Movilidad sostenible

Intermodalidad "tren+bici"

Cicloturismo

Vías verdes

Sistemas de Información Geográfica

\section{KEYWORDS}

Sustainable Mobility

Intermodality "train+bike"

Cycle tourism

Greenways

Geographic Information Systems

\section{RESUMEN}

El auge del cicloturismo se apoya en el uso de itinerarios no motorizados, lo que favorece una nueva tipología turística que posibilita la dinamización de zonas rurales y periféricas. En la actualidad los estudios de movilidad sostenible contemplan, en gran medida, la intermodalidad, sobre todo entre medios de transporte de carácter público, poco contaminantes y colectivos, como es el caso del ferroviario.

Andalucía dispone de una enorme variedad de itinerarios no motorizados (vías pecuarias, caminos rurales, vías verdes...) asociados a espacios de gran valor paisajístico y patrimonial. El objetivo principal de esta investigación es el establecimiento de una metodología que permita identificar los vínculos existentes entre líneas férreas en uso y estos itinerarios.

Para ello, a nivel metodológico, se ha realizado primero un estudio de proximidad mediante la herramienta Buffer Geoprocessing, y posteriormente un análisis de redes para medir la accesibilidad a través de la extensión Network Analyst, en ambos casos del programa ArcGIS, aplicados al Sistema de Información Geográfica que se ha implementado.

Sus resultados principales están en relación con la determinación de rutas propicias para los potenciales usuarios de la intermodalidad "tren+bici" en Andalucía. Y sus conclusiones son, por consiguiente, indicativas de cara a posteriores estudios de detalle.

\begin{abstract}
The rise of cycle tourism is based on the use of non-motorized itineraries, which favours a new tourist typology that makes possible the revitalization of rural and peripheral areas. At present, studies of sustainable mobility consider, to a large extent, intermodality, especially among public transportation means, which are not very polluting and collective, as in the case of railways.

Andalusia has a huge variety of non-motorized itineraries (livestock trails, rural roads, greenways ...) associated with areas of great scenic and heritage value. The main objective of this research is the establishment of a methodology that allows to identify the existing links between railway lines in use and these itineraries.

To do this, at the methodological level, a proximity study was carried out first using the Buffer Geoprocessing tool, and subsequently a Network Analysis to measure accessibility through this extension, in both cases of the ArcGIS program, applied to the Geographic Information System that has been implemented.

Its main results are related to the determination of favourable routes for potential users of the "train+bike" intermodality in Andalusia. In addition, its conclusions are, therefore, indicative for further studies of detail.
\end{abstract}




\section{INTRODUCCIÓN}

En la actualidad, el auge del cicloturismo y de las actividades recreativas en la naturaleza a través del uso de itinerarios no motorizados combinados con transportes públicos ha favorecido una nueva tipología turística que hace posible la dinamización de zonas rurales, dando lugar a un modelo económico sostenible, sobre todo en países europeos como Francia, Alemania y Suiza.

Los estudios de movilidad contemplan, como parte esencial, la intermodalidad entre distintos tipos de transporte, especialmente aquéllos de carácter público, poco contaminantes y colectivos. Así podemos encontrar países que se sitúan próximos a nuestro entorno que ya tienen un largo bagaje con respecto a la intermodalidad del tren con estos itinerarios no motorizados y las actividades ecoturísticas, como queda reflejado en el informe Impacto económico del cicloturismo en Europa. Síntesis de los principales estudios realizados, de Emili Mató y Xandra Troyano (2014).

En Andalucía existe una gran variedad de itinerarios no motorizados asociados a espacios de gran valor paisajístico y patrimonial, quedando patente la gran potencialidad de estos itinerarios para el desarrollo de estas actividades. Así, el Plan Andaluz de la Bicicleta 2014-2020 (Consejería de Fomento y Vivienda, 2014), propone, para esta Comunidad Autónoma, una red ciclista básica, donde la distribución de sus espacios naturales y la red urbana son determinantes en el trazado de la misma, y, por tanto, dando soporte a estos itinerarios y a las actividades turísticas, deportivas y de ocio que puedan realizarse en ellos.

La elección y potencialidad de estos itinerarios no motorizados dependerá, en gran medida, de la distancia que exista a los núcleos intermodales, principalmente estaciones de tren, por ser éste considerado un transporte público y sostenible. Como decíamos, la oferta de itinerarios no motorizados en Andalucía es muy amplia, teniendo gran potencialidad la rehabilitación de las antiguas vías de ferrocarril que hoy en día se encuentran en desuso, y que conocemos como vías verdes (Aycart, C., 2001), aunque también se dispone de caminos rurales, senderos y vías pecuarias.

Con esta aportación se pretende, por medio de su metodología, estableciendo un procedimiento que sirva para identificar los vínculos existentes entre líneas férreas en uso e itinerarios no motorizados. En este sentido los Sistemas de Información Geográfica (SIG) determinarán los potenciales núcleos intermodales a partir de una serie de requisitos y variables que establecerán cuáles serán, más adelante, los casos de estudio.

La identificación de los núcleos potencialmente óptimos de intermodalidad entre líneas férreas e itinerarios no motorizados servirá para poder realizar posteriores estudios de mayor detalle sobre los ámbitos seleccionados. En todo caso, este primer momento de la investigación que ahora se inicia permite obtener un diagnóstico básico de la situación actual, que facilite la toma decisiones a la hora de impulsar estos espacios intermodales. Se trata de generar ejes articuladores que interconectan medio rural y espacios periféricos, y que tengan como premisa fundamental una movilidad intermodal colectiva y sostenible, que coadyuve a un desarrollo socio-económico adecuado, basado en actividades cicloturísticas, recreativas y de ocio.

Según Martín Cejas y Martínez Hernández (2017), la relación entre el turismo y los transportes no sólo se limita a la posibilidad de llegar al destino, sino que se mantiene y se amplía una vez que el turista se dispone a disfrutar de su tiempo en dicho destino, pudiéndose apreciar ejemplos en estados europeos como Francia, Alemania y Suiza que cuentan con larga trayectoria en el uso de la bicicleta como modelo turístico y dinamizador económico del territorio, siendo nuestros competidores para atraer hacia sus itinerarios a usuarios de la actividad ecoturística y ciclista.

En este sentido EuroVelo es una red ciclista extensa, compuesta por 15 rutas de larga distancia, implantada y coordinada por la Federación Europea de Ciclistas (ECF) que se pretende que esté finalizada en 2020, pasando varias rutas importantes por los diferentes países europeos y contando con estructuras modernizadas y de fácil accesibilidad e información detallada de estos itinerarios (Freire, J., 2018).

Otro factor importante a destacar es la combinación intermodal de la utilización del "tren+bici" como algo muy habitual en Centroeuropa, donde los trenes están adaptados al desplazamiento de cicloturistas. También, en Francia, se ha creado un sello de calidad para las actividades comerciales y turísticas que se desarrollan alrededor de las estaciones de tren y de estos itinerarios no motorizados, generando una red 
de desarrollo económico ligada a los usuarios de la bicicleta y disfrute de la naturaleza, como potenciadores turísticos de ámbitos rurales y creadores de corredores que combinan sinergias diferentes, enlazando asentamientos con diferente patrimonio geomorfológico, industrial, etnográfico y cultural, que dan singularidad a cada itinerario.

En el caso andaluz, en la actualidad, se están habilitando muchos itinerarios para la actividad cicloturística por el potencial que tienen, tanto paisajístico como desde su vertiente económica, pero presentan un difícil acceso y falta de infraestructuras adaptadas a las actividades relacionadas con la naturaleza. Además de esto, hay escasa información sobre estos itinerarios no motorizados, la accesibilidad a los mismos (Ventura, J. et al. 2017) y los diferentes servicios que se encuentran a su alrededor, resultando aún poco atractivos para el ciclista extranjero, e incluso para el nacional, que prefiere otros destinos con mejores infraestructuras.

Todos estos factores, junto con la escasa intermodalidad del "tren+bici" entre las estaciones de tren y los itinerarios no motorizados, hacen que Andalucía pierda oportunidades para desarrollar una economía sostenible vinculada a la bicicleta, debido, en cierto modo, a la normativa existente, que condiciona el acceso al tren, y el hecho de que este medio no se encuentre todavía adaptado para los desplazamientos de cicloturistas. En definitiva, este contexto fomenta la necesidad de aplicar una metodología capaz de determinar la potencialidad en Andalucía de aquellos itinerarios que favorezcan la intermodalidad entre las estaciones ferroviarias y su proximidad a estos itinerarios, creando un modelo de interpretación científica de los datos, siendo éstos obtenidos de una combinación de fuentes de distinta procedencia, junto con un soporte cartográfico que proporcione alternativas y ayude a la toma de decisiones estratégicas en cualquier parte del territorio andaluz.

\section{AUGE DEL CICLOTURISMO Y MARCO TEÓRICO}

Según se ha dicho, en las últimas décadas, el cicloturismo ha experimentado un fuerte auge como nueva modalidad turística, ya que es capaz de integrar, y por lo tanto de potenciar, diferentes elementos territoriales, abordando una visión global del espacio y desconcentrando la presión turística en puntos concretos, para diversificarla a lo largo de itinerarios de gran valor patrimonial, paisajístico y singularidad.

Países de Europa Occidental, como Bélgica y Holanda, comenzaron a fomentar el uso de la bicicleta en los años setenta del pasado siglo XX, originando una fuerte demanda del uso de ésta para la realización de desplazamientos, tanto de uso cotidiano como de carácter integrador entre naturaleza y actividades recreativas (Pucher, J. et al., 2008). Este hecho hace que, en la actualidad, sean éstos los países que cuentan con más ciclistas dentro de la Unión Europea (Serra, M., 2016), destacando por fomentar el uso de vías ciclistas como motor turístico, y favoreciendo la intermodalidad con transportes públicos colectivos, como es el tren fundamentalmente.

En los últimos años Francia y Alemania están incrementando sustancialmente su atracción para cicloturistas, pues, aunque empezaron con posterioridad en la creación de rutas y redes para la realización de actividades relacionadas con la bicicleta, han sido capaces de atraer a un turismo respetuoso con la naturaleza, y han creado una serie de servicios e infraestructuras de alta calidad alrededor de éstas, donde el usuario encuentra itinerarios con buena accesibilidad, así como un alto valor paisajístico y etnográfico, con una notable información del recorrido. Se trata de itinerarios bien señalizados, que conectan poblaciones con servicios. De esta forma relacionamos conceptos como capital territorial con cicloturismo y economía sostenible, y, como indica Fernández Latorre (2015): "confirmamos que hay mayores infraestructuras y aspectos económicos que se encuentran en regiones turísticas más maduras".

Una parte del éxito de estos itinerarios no motorizados en estos países se debe a que han sabido conectar el transporte público con estos destinos, es decir, la intermodalidad entre el tren, sobre todo, y el uso de la bicicleta. Así, en asociaciones ciclistas de los mismos, se puede encontrar información sobre el transporte ferroviario, la normativa existente sobre el desplazamiento de bicicletas en los vagones, estaciones, frecuencias de paso y precios.

Los ferrocarriles nacionales franceses presentan un volumen de trenes y frecuencia bastante altos, por lo que la oferta de los que admiten bicicletas es grande, evitándose así incertidumbres a la hora de realizar des- 
plazamientos, donde el transporte de bicicletas está permitido no sólo en los trenes regionales y de cercanías de la Región de París, donde no se paga por ello, sino que se admite bajo tres modalidades distintas en los de Grandes Líneas (Corail en sus diferentes variantes) e incluso Alta Velocidad. Algunos de estos trenes de larga distancia admiten gratuitamente bicicletas desmontadas y embaladas y otros (Corail Intercités) sin embalar.

En Alemania se pueden llevar bicicletas en los trenes locales y la mayoría de los trenes interurbanos, pero no se pueden transportar en trenes de Alta Velocidad. La Deutsche Bahn (DB), en la región alemana de Waden Wurtenberg, funciona, sobre todo, en la zona de la Selva Negra, cerca de Freiburg. Por otro lado, en algunas ciudades, como en la suiza Basilea, los tranvías tienen soportes para bicicletas. Así, en la Confederación Helvética, la compañía de Ferrocarriles Federales Suizos (en alemán, Schweizerische BundesBahnen) ofrece servicios de transporte de bicicletas, y los autobuses de la compañía postal y barcos, así como los transportes de montaña, están bien conectados con el ferrocarril.

En otros estados miembros de la Unión Europea, como es Reino Unido, encontramos la National Cycle Network, que es una red de itinerarios no motorizados con una longitud de unos 16.000 km (Insall, P., 2004), y que la organización Sustrans cifraba ya en 16.755 millas (unos 26.520 km) en 2018, para el desarrollo de actividades recreativas, donde cualquier núcleo de población se localiza a menos de dos kilómetros de distancia de una ruta con muy buena accesibilidad, incluso para Personas con Movilidad Reducida (PMR; niños, embarazadas, personas mayores, discapacitados físicos...; Stehlíková y Řezník, 2018).

Las asociaciones ciclistas británicas tienen un fuerte poder, ya que han impulsado la creación de miles de kilómetros de itinerarios no motorizados, y, junto con las administraciones públicas, se encargan de la gestión y el mantenimiento de estos itinerarios. Estas asociaciones tienen una larga trayectoria en el fomento y promoción de estas rutas dentro de su sociedad, al igual que intentan dotarlas de calidad mejorando la oferta turística. Asociaciones ciclistas, como la mencionada Sustrans, fomenta la movilidad sostenible, siendo capaz de diseñar y mantener tramos con la ayuda de fondos públicos y voluntariado, además de implicar a las administraciones locales para que se comprometan en el desarrollo y mantenimiento de los tramos de itinerarios que les afecten.

Este caso de fuerte implicación de las asociaciones es muy parecido al de la Rails to trails conservancy de Estados Unidos, la cual es una asociación que reconvierte las antiguas vías férreas que están en desuso en itinerarios multifuncionales para actividades cicloturísticas y otras no motorizadas. Esta asociación presenta iniciativas a nivel local para la creación y gestión de nuevas rutas, pero en estos momentos esta red de itinerarios y vías verdes tiene poca continuidad en el territorio al igual que sucede aún en España, mermando por tanto la oferta cicloturística y las posibilidades de movilidad sostenible. No obstante, esta organización estadounidense ha anunciado, recientemente, una gran ruta para bicicleta de montaña (MTB) que cruzará el país de costa a costa.

Por otro lado, cabe también señalar que en Europa se están desarrollando itinerarios no motorizados que conectan el conjunto del territorio. Son los conocidos como senderos europeos transnacionales, de larga distancia, y que están compuestos por 12 rutas que atraviesan el conjunto del continente, las cuales aprovechan las antiguas infraestructuras existentes. Para que esta red de caminos se desarrolle en Europa ha sido necesaria la colaboración entre entes diferentes, tanto gubernamentales como asociaciones de senderismo y ciclismo de distintos países, que han colaborado para impulsar un turismo sostenible, combinando el capital territorial con estrategias específicas (Camagni y Capello, 2013). Así encontramos la asociación ERA, o Asociación Europea de Senderistas, que ha contribuido a que las rutas presenten un balizado único y homogéneo, encargándose de su mantenimiento, propuesta de nuevos recorridos, e información y divulgación a través de webs y de otras fuentes.

Por su parte la referida red EuroVelo, promovida por la Federación Europea de Ciclistas (European Cyclists' Federation, ECF), está compuesta por 15 rutas de larga distancia que conectan todo el territorio europeo para desarrollar actividades cicloturísticas y recreativas en el medio natural. EuroVelo tiene como objetivo conectar todos los países que forman la Unión Europea mediante itinerarios no motorizados de alta calidad y que sean seguros para los usuarios de estas grandes rutas (Weston, R. et al., 2012). Para ello existen parámetros que se tienen que cumplir para incorporar las rutas a la red. Estas especificaciones van desde aspectos generales sobre distancias mínimas de la ruta, pendientes máximas, señalización, y que 
impliquen como mínimo a dos estados; pero también existen requisitos en cuanto a estructuras y servicios que son clave para garantizar la seguridad y el bienestar de los usuarios de estos itinerarios.

España se ve afectada por 3 de estos itinerarios cicloturistas paneuropeos, en concreto, por la Ruta de los Peregrinos (la $n^{\circ} .3$ ), en la práctica el Camino francés a Santiago de Compostela, y por la 1 y la 8. Estas dos últimas discurren en concreto por la Comunidad andaluza: la Ruta de la Costa Atlántica $\left(n^{\circ}\right.$. 1), que debe recorrer de Norte a Sur la provincia de Huelva y enlazar con el Algarve portugués salvando la frontera que supone el río Guadiana; y la Ruta Mediterránea $\left(n^{\circ}\right.$. 8), que transita próxima al litoral mediterráneo andaluz (provincias de Almería, Granada, Málaga y Cádiz), hasta concluir en la milenaria capital gaditana.

Por su parte debemos señalar, en relación con estos itinerarios, que disponemos ya de estudios muy recientes sobre el impacto económico de las actividades cicloturísticas en los territorios que se ven afectados por estas grandes rutas, y que indican que son un proyecto con gran futuro, como bien enfatiza Nicolas Mercat (2018), destacando tanto los impactos económicos directos, la importancia de la bicicleta como modelo turístico, y también sus repercusiones en salud y seguridad.

Otros países externos a la Unión Europea, como Australia, cuentan con estudios sobre el tamaño y alcance de la actividad cicloturística como motor turístico sostenible, poniendo de manifiesto el creciente interés del uso de la bicicleta y el potencial impacto económico que supone, sobre todo para las zonas rurales. Así, en el trabajo Cycle Tourism in Australia: An investigation into its size and scope (Faulks, P. et al., 2006), se realiza un diagnóstico sobre el alcance del turismo en bicicleta, y se cuantifica su potencial en función de su escala nacional, regional o local, en el que los resultados obtenidos sobre patrones de uso y gastos en estos itinerarios proporcionan información de gran importancia para valorar sus potencialidades, pero también las debilidades a corregir, para mejorar las infraestructuras existentes y la oferta cicloturística, así como su repercusión económica en el territorio, ya que con ello se podrán identificar mejor qué inversiones serán más adecuadas. En el cuadro 1, procedente de dicho informe, se pone de manifiesto, a modo de resumen, cuáles son los factores que fomentan el cicloturismo.

En Andalucía contamos con diversos estudios sobre el potencial del cicloturismo como sector emergente (Rebollo, S., 2003; Luque, P., 2012; y Fernández, F., 2015), destacándose a las vías verdes como las infraestructuras deportivas del futuro. Otros autores, como Aycart Luengo (2006), también pone en valor estos soportes, que tienen como objetivo "la reutilización de trazados ferroviarios en desuso como itinerarios no motorizados que conecten las poblaciones, los espacios naturales y los puntos de interés histórico-artístico, acercando a ellos de forma sostenible al ciudadano".

Así pues, las sinergias entre cicloturismo, vías verdes y otros tipos de itinerarios no motorizados, junto con una buena accesibilidad desde el transporte público ferroviario, son un ejemplo de desarrollo sostenible (Ventura, J. y Gavira, A., 2016), con muy buenos resultados tanto en Europa como en aquellos otros lugares donde se han implantado.

Por su parte el Plan Andaluz de la Bicicleta (PAB, 2014-2020) pretende implantar una red de vías ciclistas en Andalucía que sea motor para la creación de un nuevo modelo de desarrollo turístico y de movilidad sostenible, y se ha tenido en consideración para la elaboración del Plan General de Turismo Sostenible de Andalucía Horizonte 2020, aprobado en 2016 por parte de la Consejería de Turismo y Deporte.

Dentro del PAB se pueden diferenciar objetivos desde el punto de vista del conjunto de la Comunidad Autonómica, pero también a escala metropolitana e incluso urbana, donde se consolidan rutas cicloturísticas existentes y además se integran y conectan los diferentes territorios con los nuevos itinerarios propuestos, potenciándose la capacidad de atracción de sus recursos naturales, gastronómicos, artísticos y etnográficos.

Así pues, el Plan Andaluz de la Bicicleta (PAB) tiene como uno de sus objetivos difundir la oferta de la red cicloturística. Para ello es necesario crear una red amplia y darla a conocer a las empresas del sector $y$, de esta manera, adaptar su oferta a los servicios necesarios para el cicloturismo, diversificando diferentes productos alrededor del sector de la bicicleta.

Se procura, en definitiva, consolidar e integrar las iniciativas existentes con las nuevas propuestas turísticas, creando itinerarios ciclistas temáticos, en los que se ponga en valor el patrimonio interior de las áreas rurales y periféricas, como por ejemplo rutas de carácter monumental, industrial o natural, entre otras. 
Cuadro 1. Factores que facilitan las experiencias cicloturísticas.

\begin{tabular}{|c|c|c|}
\hline \multirow{7}{*}{ Atracciones } & \multirow{4}{*}{ Atracciones construidas } & Pueblos \\
\hline & & Restaurantes \\
\hline & & Sitios históricos \\
\hline & & Alojamientos \\
\hline & \multirow{3}{*}{ Atracciones naturales } & Paisajes \\
\hline & & Bosques \\
\hline & & Lagos \\
\hline \multirow{7}{*}{ Información } & \multirow{6}{*}{ Mapas } & Folletos y dispositivos electrónicos \\
\hline & & Debe informarse sobre: \\
\hline & & Alojamientos \\
\hline & & $\begin{array}{l}\text { Localización de baños, tiendas y almacenamiento de } \\
\text { bicicletas }\end{array}$ \\
\hline & & Descripción del terreno y clasificación de las pistas \\
\hline & & Atracciones clave \\
\hline & Señalización de rutas & \\
\hline \multirow{6}{*}{ Rutas } & \multirow{5}{*}{ Variedad de longitudes } & Rutas circulares de ida y vuelta en recorridos tranquilos \\
\hline & & $\begin{array}{l}\text { Rutas de una noche con varios alojamientos a lo largo del } \\
\text { recorrido }\end{array}$ \\
\hline & & $\begin{array}{l}\text { Rutas largas con alojamientos y comodidades para el } \\
\text { usuario }\end{array}$ \\
\hline & & $\begin{array}{l}\text { Rutas que enlazan sitios de interés geográfico, histórico o } \\
\text { cultural }\end{array}$ \\
\hline & & Rutas que conectan pueblos y aldeas. \\
\hline & Variedad de terrenos & \\
\hline \multirow{3}{*}{ Transporte público } & \multirow{3}{*}{$\begin{array}{l}\text { Que permitan el } \\
\text { transporte de bicicletas }\end{array}$} & Trenes \\
\hline & & Autobuses \\
\hline & & Aviones \\
\hline \multirow{4}{*}{ Compañías turísticas } & & Pueden proporcionar: \\
\hline & & Guías turísticos \\
\hline & & Transporte de equipos y equipaje \\
\hline & & Apoyo de servicios, alojamiento y comida \\
\hline Alquiler de bicicletas & & Deberían estar disponibles cerca de las rutas \\
\hline Alojamiento & $\begin{array}{l}\text { Alojamiento amigable } \\
\text { para ciclistas }\end{array}$ & Pueden estar identificados para promover el cicloturismo \\
\hline \multirow[t]{2}{*}{$\begin{array}{l}\text { Comodidades en tiendas y } \\
\text { aparcamientos }\end{array}$} & $\begin{array}{l}\text { Almacenamiento seguro } \\
\text { de bicicletas y equipos }\end{array}$ & $\begin{array}{l}\text { En cafés, restaurantes y alojamientos (incluidos campings } \\
\text { y hoteles) }\end{array}$ \\
\hline & $\begin{array}{l}\text { Aparcamiento seguro de } \\
\text { vehículos }\end{array}$ & $\begin{array}{l}\text { En cafés, restaurantes y alojamientos (incluidos campings } \\
\text { y hoteles) }\end{array}$ \\
\hline
\end{tabular}

Fuente: Hunter Cycling Network (2005), recogido por Faulks, P. et al., 2006. 
De esta forma el programa turístico del PAB propone recorridos en bicicleta con distinta temática a diferentes escalas territoriales, así como la creación del distintivo de calidad que presentan otros países como Francia, tanto para los destinos turísticos como para la red de empresas e infraestructuras que dan cobertura a los itinerarios no motorizados.

Ahora bien, no deja de ser sumamente significativo que a fecha del primer trimestre de 2019 sólo se hayan construido 142,2 km de carriles-bici para una red que, en su conjunto, se establecía en 4.392 km; o que a unos 18 meses de su finalización cronológica sólo se hayan ejecutado 261,9 millones de euros de los 446,2 contemplados en el capítulo de inversiones. El nuevo Ejecutivo andaluz (desde enero de 2019) ha indicado, no obstante, su voluntad de reactivar este Plan.

\section{OBJETIVOS Y METODOLOGÍA DEL ESTUDIO REALIZADO}

La hipótesis de partida consiste en que para entender la potencialidad de la intermodalidad de las líneas férreas con los itinerarios no motorizados para la práctica del cicloturismo, todo dependerá, en gran medida, de la distancia de desplazamiento o proximidad entre las estaciones de tren y el acceso a estos itinerarios. Emili Mató y Xandra Troyano, en el ya referido informe de Impacto Económico del cicloturismo en Europa. Síntesis de los principales estudios realizados, consideran que la distancia recorrida en diez minutos por el cicloturista es el límite aceptable para llegar desde una estación de transporte público al inicio de un itinerario, de manera que más allá de ese tiempo, el recorrido comienza a convertirse en disuasorio. Es por ello que consideran que, para el usuario de la bicicleta, la distancia máxima a recorrer antes de empezar el itinerario propiamente dicho sería de 3,2 km, lo que implica una velocidad media de desplazamiento de 19,2 km/h.

El estudio por proximidad se va a completar aquí con otro de accesibilidad mediante un análisis de redes, a través de la extensión Network Analyst de ArcGIS, que permite establecer distintas isócronas a partir de la estación ferroviaria en uso según su tipología de interés para este trabajo (cercanías, circulación y mixta). En este caso se ha reducido la velocidad media a un valor más cercano al de un cicloturista novel o con posible carga en sus alforjas, esto es, a $15 \mathrm{~km} / \mathrm{h}$, si bien se ha incrementado el tiempo crítico hasta los 15 minutos, según es habitual en diferentes estudios sobre accesibilidad ideal en general (Escalona y Díez, 2005) y ferroviaria en particular (Gavira y Ventura, 2003).

En suma, mediante la presente investigación se pretende alcanzar dos objetivos fundamentales:

a. Identificar los núcleos intermodales con mayores oportunidades para el desarrollo de actividades cicloturísticas, así como los itinerarios no motorizados que se encuentran en las proximidades de estaciones ferroviarias, para poderlos abordar a posteriori en profundidad.

b. Determinar qué rutas podrían ser las más atractivas, al permitir el desarrollo de actividades recreativas en contacto con la naturaleza, pudiéndose diseñar itinerarios tanto de un día como otros que impliquen varias pernoctaciones.

Andalucía presenta una superficie de $87.286 \mathrm{~km}^{2}$, y posee una gran variedad de paisajes y estructuras geomorfológicas diferenciadas, junto con unos rasgos climáticos en general benignos para las actividades al aire libre. Estas características, unidas a la gran diversidad de itinerarios no motorizados que se interconectan, dotan a la región de un enorme potencial para el establecimiento de núcleos intermodales entre líneas férreas en funcionamiento y rutas dedicadas al desarrollo de actividades cicloturísticas y recreativas.

De este modo contamos con una densísima red de vías pecuarias (entra las que destacan por su anchura las cañadas reales), senderos (algunos de ellos calificados como de Gran Recorrido) y líneas férreas en desuso, conocidas como vías verdes cuando están debidamente acondicionadas; lo que representa un gran potencial para la mencionada práctica del cicloturismo, en muchos casos con longitudes importantes para el desarrollo de actividades recreativas en la naturaleza (ocio activo), bien de un solo día o, cuando son de mayor recorrido, con las consiguientes pernoctaciones.

Así pues estudiaremos y seleccionaremos aquellas estaciones de tren para el transporte de pasajeros que se encuentren a una distancia de menos de $3 \mathrm{~km}$ de estos itinerarios no motorizados, por medio de 
Buffer Geoprocessing , en coherencia con los 3,2 km como distancia crítica señalada con anterioridad, con el objetivo de crear un modelo que sirva como base para que, al utilizar y combinar distintas variables, se puedan realizar diferentes diagnósticos y, por lo tanto, predecir y resolver problemas que se planteen en estos núcleos intermodales de "tren+bici".

Los Sistemas de Información Geográfica, que contienen información espacial, más la utilización de distintos criterios (distancia, accesibilidad en tiempo,...), nos van a permitir que se den diversas interrelaciones entre las diferentes capas o variables del estudio, pudiéndose constatar la potencialidad del método y la capacidad de análisis sobre las conexiones de los elementos que se distribuyen en el territorio, lo que origina una información muy valiosa para las previsiones y actuaciones futuras en materia de movilidad en estos itinerarios. Se trata, además, de una línea de investigación muy actual y aplicada a escala regional, como se constata en trabajos recientes, como los de Pedrosa, A. et al. (2019).

Con este tipo de análisis podemos identificar, al igual que las potencialidades o fortalezas de estos recorridos, también los aspectos que debilitan o amenazan que los territorios se desarrollen o no, y, por lo tanto, que afectan a las posibilidades de una economía sostenible en el medio rural.

La fuente fundamental de este estudio será DERA (Datos Espaciales de Referencia de Andalucía), que es un repertorio de bases cartográficas de diferente naturaleza geométrica (puntos, líneas, polígonos, imágenes raster) referidas al territorio andaluz. Se presenta en bloques temáticos que permiten el acceso centralizado a información de muy distinta procedencia, con garantía de actualización, coherencia geométrica y continuidad territorial. La información se encuentra accesible por capas en formato shapefile (.shp), en sistema de referencia geodésico ETRS89 y proyectadas en UTM huso 30. Es un producto del Instituto de Estadística y Cartografía de Andalucía (IECA), realizado con financiación de la Unión Europea a través del Fondo Europeo de Desarrollo Regional (FEDER).

En su Memoria Técnica se reflejan las diferentes variables, con su tipo de geometría, denominación, códigos y distintos atributos. Exponemos a continuación, mediante el cuadro 2, las capas que se han utilizado para la elaboración de los mapas resultantes de este estudio, perteneciendo, mayoritariamente, al grupo correspondiente a "Viario", si bien también se ha empleado el de "Infraestructuras de transportes" (estaciones de ferrocarril) y el dedicado a "Divisiones Administrativas" (términos municipales).

Cuadro 2. Características básicas de las capas utilizadas de DERA.

\begin{tabular}{|c|c|c|c|c|}
\hline Nombre de la capa & $\begin{array}{l}\text { Tipo de } \\
\text { geometría }\end{array}$ & Grupo & Entidades que se emplean & Metadatos básicos \\
\hline \multirow{3}{*}{$\begin{array}{l}\text { Estaciones de } \\
\text { ferrocarril }\end{array}$} & \multirow{3}{*}{ Puntual } & \multirow{3}{*}{$\begin{array}{l}\text { Infraestructuras de } \\
\text { transportes }\end{array}$} & Estación de circulación & \multirow{3}{*}{$\begin{array}{l}\text { Localización tanto de } \\
\text { estaciones, apeaderos y } \\
\text { descargaderos de ferrocarril } \\
\text { como de instalaciones } \\
\text { logísticas y técnicas }\end{array}$} \\
\hline & & & Estación mixta & \\
\hline & & & Estación de cercanías & \\
\hline \multirow{3}{*}{ Red de carreteras } & \multirow{3}{*}{ Lineal } & \multirow{3}{*}{ Viario } & Carretera convencional & \multirow{3}{*}{$\begin{array}{l}\text { Información acerca del } \\
\text { trazado de la red de } \\
\text { carreteras existente en } \\
\text { Andalucía }\end{array}$} \\
\hline & & & Viario urbano & \\
\hline & & & Caminos & \\
\hline Caminos $^{1}$ & Lineal & Viario & Camino & $\begin{array}{l}\text { Información sobre el trazado } \\
\text { del viario rural que da acceso } \\
\text { a las principales zonas de } \\
\text { diseminado y edificación } \\
\text { rural aislada }\end{array}$ \\
\hline
\end{tabular}

1. Entendemos que esta capa lineal del viario complementa, necesariamente, a la entidad "Caminos" de la Red de carreteras, de cara a un mejor estudio de accesibilidad a los itinerarios no motorizados, aunque su fecha de actualización (2007) sea anterior a la de la segunda (2012). 


\begin{tabular}{|c|c|c|c|c|}
\hline Nombre de la capa & $\begin{array}{c}\text { Tipo de } \\
\text { geometría }\end{array}$ & Grupo & Entidades que se emplean & Metadatos básicos \\
\hline \multirow{2}{*}{ Red de ferrocarriles ${ }^{2}$} & \multirow{2}{*}{ Lineal } & \multirow{2}{*}{ Viario } & ffcc vía doble & \multirow{2}{*}{$\begin{array}{l}\text { Trazado de la red } \\
\text { ferroviaria }\end{array}$} \\
\hline & & & ffcc vía única & \\
\hline Vías pecuarias & Lineal & Viario & Cañada & $\begin{array}{l}\text { Trazado de } \\
\text { las vías pecuarias de } \\
\text { Andalucía incluyendo datos } \\
\text { acerca de su tipología, } \\
\text { anchura, longitud, etc. }\end{array}$ \\
\hline Senderos & Lineal & Viario & Sendero & $\begin{array}{l}\text { Trazado de los } \\
\text { itinerarios peatonales } \\
\text { señalizados existentes en } \\
\text { Andalucía, incluyendo los } \\
\text { senderos de gran } \\
\text { recorrido }\end{array}$ \\
\hline Vías verdes & Lineal & Viario & Vía verde & $\begin{array}{l}\text { Trazado de las vías } \\
\text { verdes de Andalucía, } \\
\text { formadas por trazados } \\
\text { ferroviarios en desuso que } \\
\text { han sido reconvertidos } \\
\text { en itinerarios cicloturistas y } \\
\text { senderistas }^{3}\end{array}$ \\
\hline Términos municipales & Poligonal & $\begin{array}{l}\text { Divisiones } \\
\text { Administrativas }\end{array}$ & Municipio & $\begin{array}{l}\text { Delimitación de los } \\
\text { municipios andaluces }\end{array}$ \\
\hline
\end{tabular}

Fuente: Elaboración propia a partir del Modelo de Datos de DERA.

\section{RESULTADOS DEL TRABAJO: UNA CARTOGRAFÍA PARA LA TOMA DE DECISIONES}

\subsection{Itinerarios disponibles a menos de $3 \mathrm{~km}$ de estaciones de ferrocarril en funcionamiento}

Los resultados cartográficos obtenidos para aquellos itinerarios que se encuentran a una distancia máxima de $3 \mathrm{~km}$ de las estaciones de ferrocarril en uso y que pueden permitir la práctica de la actividad cicloturística aparecen en el mapa 1.

En primer lugar, debemos destacar que los itinerarios no motorizados en los que ya se han puesto en marcha estas iniciativas son, hasta el momento, las siguientes vías verdes:

- Vía Verde del Aceite, con un recorrido de 127,36 km, empezando su trayecto en Puente Genil, en la provincia de Córdoba, y terminando en Jaén capital. Este itinerario presenta fácil acceso desde estaciones de ferrocarril y, por lo tanto, el desplazamiento en bicicleta desde la red férrea es muy factible. Se trata, en estos momentos, de una oferta muy dinámica y atractiva para el usuario, resultado de la fusión de tres antiguas vías verdes, contiguas pero segmentadas, impulsándose así una economía de escala que es sumamente importante para el sector de la movilidad sostenible.

- Vía Verde de la Campiña, con un recorrido de 91,92 km; itinerario no motorizado que empieza en la localidad de Marchena, en la provincia de Sevilla, llegando hasta las proximidades de Córdoba capital. Además, en el origen de este itinerario convergen cuatro cañadas reales, como son: la Cañada Real de Sevilla, con 5,10 km de recorrido por el municipio marchenero; la de Morón, con 10,31 km en el mismo ámbito; la de Pruna, de 14,04 km; y la propiamente denominada de Marchena (12 km), y

2. La información sobre ferrocarriles abandonados o en desuso nos ha sido facilitada por la Fundación de los Ferrocarriles Españoles (FFE), organismo dependiente de RENFE y promotor del Programa Vías Verdes en el conjunto del Estado.

3. Capa actualizada con información facilitada asimismo por la referida Fundación de los Ferrocarriles Españoles (FFE). 


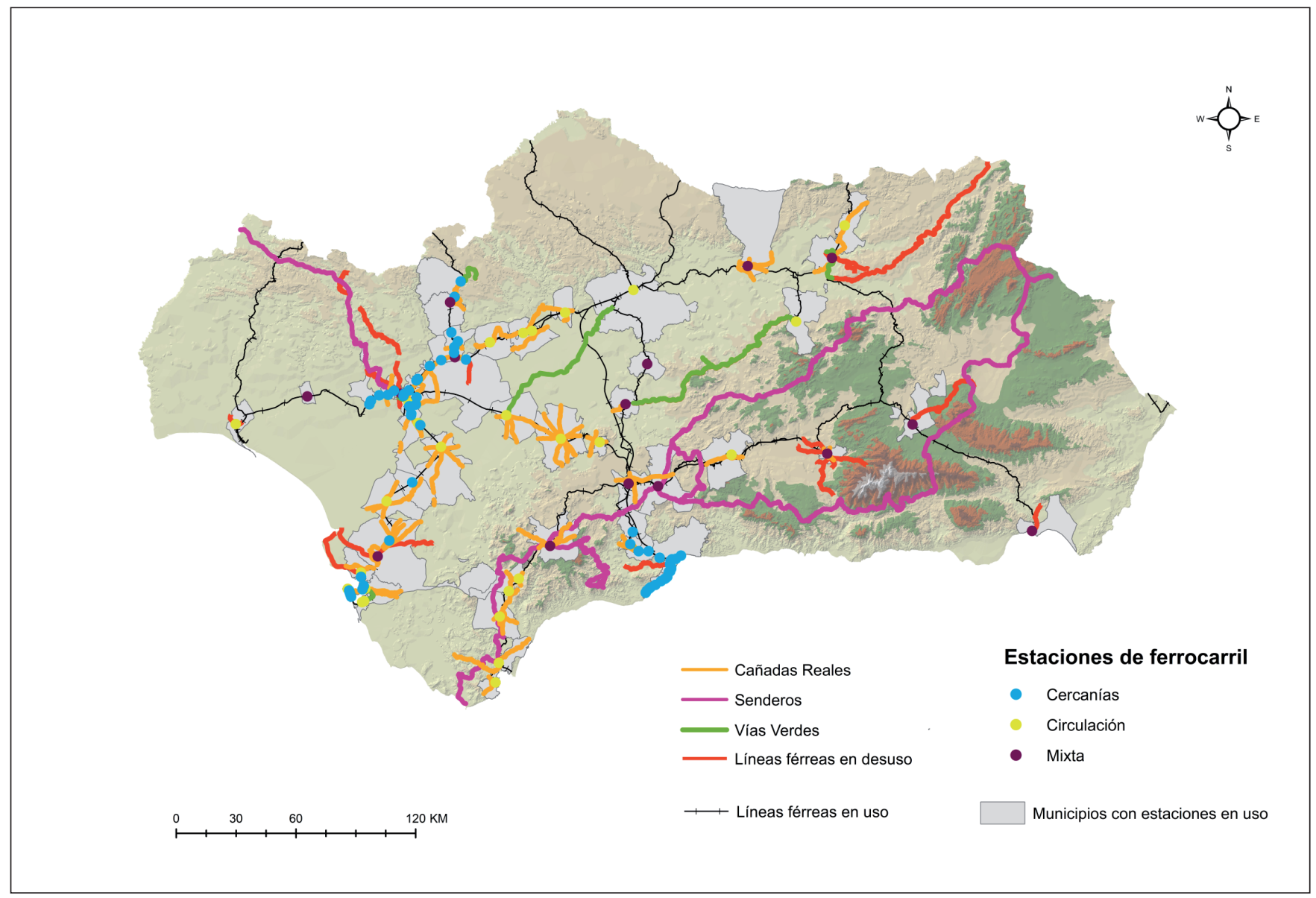

Mapa 1. Itinerarios disponibles a $3 \mathrm{~km}$. de las estaciones de ferrocarril. Fuente: Elaboración propia a partir de datos de DERA y de la Fundación de Ferrocarriles Españoles.

que se une a la Cañada Real de Osuna, llegando a este pueblo, que cuenta también con estación de ferrocarril.

- Vías verdes de Linares y de Guadalimar, con un recorrido la primera de 6,61 km y la segunda de 15,31 km sobre el antiguo trazado de la línea férrea Baeza-Utiel, que dispone de un total de 143,76 km (Cebrián, F., 2011). Se tiene acceso a las mismas a través de la estación de Linares-Baeza, donde convergen además la Cañada Real de Guadalimar, con 25,97 km de recorrido, y líneas férreas ya desmanteladas, entre las que destaca el antiguo tren Linares-Úbeda-Baeza, con 41,73 km de longitud.

- Vía Verde de la Sierra Norte de Sevilla, a la que se tiene acceso desde la estación de ferrocarril de Cazalla-Constantina (inicialmente Los Prados-Cazalla, y en la actualidad última parada septentrional de la línea C-3 del Área de Cercanías RENFE de Sevilla4), presentando un recorrido de 18,28 km, y discurriendo en paralelo durante parte de su trazado con la Cañada Real de la Rivera del Huéznar, que tiene $16 \mathrm{~km}$ y que llega hasta la estación de ferrocarril de Fábrica de El Pedroso, donde también converge con la Cañada Real de Lora a las Minas (en dirección al municipio de Villanueva del Río y Minas), con $9 \mathrm{~km}$ de longitud por el término de El Pedroso. Estas sinergias favorecen que este itinerario no motorizado (todo el mismo inserto en un espacio natural protegido con distintas figuras, entre las

4. En este sentido debemos indicar que, gracias a mejoras horarias recientes, la distribución actual durante los fines de semana es más propicia para el cicloturismo, pues permite llegar a Cazalla-Constantina a las 10:32 h., disponiéndose de un último tren de retorno a las 17:50 h. en horario de verano; lo que permite una estancia de unas 7 horas, suficiente para el recorrido ida y vuelta de la actual vía verde, así como tiempo para el descanso y avituallamiento. 
que destacan el Parque Natural Sierra Norte de Sevilla y la Reserva de la Biosfera Dehesas de Sierra Morena ${ }^{5}$ ) pudiera ampliar su recorrido y se tuviera acceso a él desde diferentes puntos.

- Vías verdes de Puerto Real-San Fernando y de Matagorda, que se localizan ambas en la Bahía de Cádiz, teniendo la primera un recorrido de $8,25 \mathrm{~km}$, y disponiendo la segunda de 3,55 km. El acceso a la Vía Verde de Puerto Real-San Fernando se realiza desde la estación de San Fernando, donde convergen además dos cañadas reales: la de Paterna, con 18,65 km; y la de Medina, de 15,98 km. Por su parte el acceso a la Vía Verde de Matagorda tiene lugar a través de la estación de ferrocarril de la Universidad, en Puerto Real, y se encuentra enlazada en su recorrido con la Cañada Real de Matagorda, que posee una longitud de 5,66 km.

- Vía Verde de Itálica, que posee un recorrido de sólo 1,7km, y a la que se puede acceder desde la estación de ferrocarril de La Cartuja, en la ciudad de Sevilla, y también por la estación de Camas. Una de las características que diferencia esta vía verde del resto es que es interurbana y, por lo tanto, permite una gran afluencia de usuarios potenciales. Además, en ella convergen otros itinerarios no motorizados que deberían añadirse y ampliar su recorrido actual, como son: el Cordel de Buernas, con una longitud de 148,82 km, que pertenece a un sendero de Gran Recorrido (GR); el tren desmantelado Aznalfarache-Cala, con 81 km de longitud total; y el ferrocarril en desuso Camas-Aznalcóllar, con $30,10 \mathrm{~km}$ de trazado.

También podemos reflejar aquí las potencialidades que presenta el tramo de ferrocarril en desuso entre Guadix y Baza, todo él en la provincia de Granada, y que forma parte del itinerario regional Eje 4, denominado "Intrabético", dentro de las propuestas del PAB. Pertenece a la línea abandonada entre Guadix (Granada) y Almendricos (Murcia), donde ya se han realizado distintas actuaciones de adaptación a vías verdes acondicionadas: Sierra de Baza, Valle del Almanzora y Huércal-Overa (estas dos últimas en la provincia de Almería).

La red de cañadas reales aumenta entre las estaciones de Bobadilla y Antequera, donde encontramos: la Cañada Real Sevilla-Málaga, con un recorrido de 29,94 km, y que enlaza con el Sendero de Gran Recorrido (GR) Europeo E-4; y la Cañada Real de Granada, con un trazado de 15,74 km que conecta también con el mismo Sendero GR Europeo E-4. Igualmente son significativas las cañadas reales existentes entre las estaciones de Jimena de la Frontera y Ronda, como son: la Cañada del Campo de Gibraltar, de 9 km; la Cañada Real de Gaucín (18,64 km); y la Cañada de Granada y Córdoba, con 16,03 km. Por otro lado, la Cañada Real de Soria parte de la estación de Posadas hacia Córdoba ciudad, con un recorrido 30,17km.

Con respecto a las líneas férreas en desuso destacan las siguientes:

- Desde la estación de Jerez de la Frontera, correspondiendo al denominado Ferrocarril de la Sierra, que discurriría hasta Almargen (en Málaga), y que se enmarcaba dentro del planteamiento militar de conectar las bases marítimas de Cádiz y Cartagena (Rincón, J., 2013). Las obras se iniciaron bajo impulso de la dictadura de Primo de Rivera. La Guerra Civil Española supuso obviamente una fuerte paralización en la ejecución de obras, y la dura posguerra no fue tampoco el mejor marco para retomar esta difícil construcción. A mediados de los sesenta del pasado siglo XX un informe del Banco Mundial determinó el definitivo abandono de las obras, estando no obstante concluidas estaciones, viaductos y túneles, a falta del tendido de vías. De los $119 \mathrm{~km}$, sólo llegó a funcionar el tramo de 21 $\mathrm{km}$ que iba de Jerez a la azucarera de Jédula. Se tendieron las vías hasta Arcos de la Frontera (31 km), pero por ellas no llegaron a pasar más que los trenes de prueba. En estos momentos existe una plataforma ciudadana muy activa que promueve la recuperación como vía verde del tramo que va de Jerez a Arcos de la Frontera. Por su parte, el de 36 km que discurre entre El Coronil y Olvera, corresponde a la denominada Vía Verde de la Sierra, la más visitada de las andaluzas según se refleja en la tesis doctoral de Pablo Luque (2012).

5. Cabe indicar aquí que, según el proyecto recientemente concluido sobre “Vías Verdes y Red Natura 2000: Divulgación de Espacios Naturales Protegidos y Geoparques a través de la Red Estatal de Vías Verdes", más del 87\% de estos itinerarios no motorizados se sitúa a menos de $5 \mathrm{~km}$ de un espacio natural protegido por la Red Natura 2000 de la Unión Europea. 
- Desde la estación de Granada, a Sierra Nevada, con 20,43km; a La Zubia, de 6,98km; y Armilla-Dúrcal $(26,48 \mathrm{~km})$.

- Desde la estación de San Julián en Málaga capital a Coín, con un recorrido de 29,77km.

- Y desde Almería a El Chorrillo, de 16,33 km.

Como es lógico, y según se aprecia en los cuadros 3 y 4 que se muestran a continuación, a mayor distancia entre las estaciones de tren y el comienzo de estos itinerarios, existe más disponibilidad de kilómetros de rutas no motorizadas para la realización de actividades cicloturísticas en los ámbitos rurales y, por lo tanto, mayor potencial para la dinamización del territorio, aunque aquí se haya decidido centrarnos en el referido valor crítico de los $3 \mathrm{~km}$, por los motivos antes aducidos.

Cuadro 3. Longitud en km, según tipos de itinerarios no motorizados, a diferentes distancias de las estaciones ferroviarias.

\begin{tabular}{|c|c|c|c|c|c|}
\hline Distancia a estación & Cañadas reales & Senderos & Vías verdes & FFCC en desuso & Total de km \\
\hline$<1 \mathrm{~km}$ & 647,74 & $1.130,43$ & 122,00 & 507,48 & $2.285,65$ \\
\hline$<2 \mathrm{~km}$ & 917,37 & $1.250,85$ & 273,91 & 866,28 & $3.034,50$ \\
\hline$<3 \mathrm{~km}$ & $1.178,45$ & $1.250,85$ & 273,91 & 974,85 & $3.404,15$ \\
\hline$<4 \mathrm{~km}$ & $1.439,06$ & $1.349,63$ & 273,91 & $1.066,69$ & $3.855,38$ \\
\hline$<6 \mathrm{~km}$ & $2.057,26$ & $1.413,37$ & 287,37 & $1.257,32$ & $4.727,95$ \\
\hline
\end{tabular}

Fuente: Elaboración propia a partir de datos de DERA y FFE.

Cuadro 4. Reparto porcentual de los tipos de itinerarios no motorizados a diferentes distancias de as estaciones ferroviarias.

\begin{tabular}{|c|c|c|c|}
\hline Distancia a estación & Cañadas reales & Senderos & FFCC en desuso \\
\hline$<1 \mathrm{~km}$ & $28,33 \%$ & $49,45 \%$ & $22,20 \%$ \\
\hline$<2 \mathrm{~km}$ & $30,23 \%$ & $41,22 \%$ & $28,54 \%$ \\
\hline$<3 \mathrm{~km}$ & $34,61 \%$ & $36,74 \%$ & $28,63 \%$ \\
\hline$<4 \mathrm{~km}$ & $37,32 \%$ & $35,00 \%$ & $27,66 \%$ \\
\hline$<6 \mathrm{~km}$ & $43,51 \%$ & $29,89 \%$ & $26,59 \%$ \\
\hline
\end{tabular}

Fuente: Elaboración propia a partir de datos de DERA y FFE.

Por su parte, en cuanto a la distribución porcentual de los tipos de itinerarios según la distancia máxima a una estación férrea en funcionamiento, se aprecia un progresivo incremento en el peso de la red de cañadas reales, que pasa de poco más del $28 \%$ a menos de $1 \mathrm{~km}$, a más del $43 \%$ a menos de $6 \mathrm{~km}$. Por el contrario, el porcentaje de senderos sigue un sentido totalmente inverso, desde el 49 al 29\%; mientras que los ferrocarriles en desuso presentan mayor estabilidad, con valores entre el 22 y el $28 \%$ en los 5 niveles de distancia que se han establecido.

6. Las Vías verdes no contabilizan en el sumatorio de esta tabla, ni presentan porcentajes específicos en el cuadro 4, puesto que, conceptualmente, no son más que itinerarios de ferrocarriles en desuso debidamente acondicionados para su uso cicloturista, senderista y otros no motorizados. 


\subsection{Análisis de redes: estudio de accesibilidad a menos de 15 minutos desde estaciones ferroviarias en uso}

Se realiza a continuación, según lo anunciado en la metodología, un análisis de redes para medir la accesibilidad desde las estaciones ferroviarias seleccionadas (cercanías, circulación y mixtas) a los distintos tipos de itinerarios en una isócrona de 15 minutos de tiempo máximo de desplazamiento a $15 \mathrm{~km} / \mathrm{h}$. La malla procede de las capas relativas a la red de carreteras andaluzas (excluidas las de doble trazado en las que por su propia tipología está prohibido el tránsito de bicicletas) y la capa específica de caminos andaluces, ya reflejadas en el cuadro 2, y que representan un total de casi $57.718 \mathrm{~km}$.

A partir de la intersección entre el buffer de $3 \mathrm{~km}$ de proximidad y la referida isócrona de 15 minutos de accesibilidad surge el mapa 2, donde, como es lógico, se simplifica la cartografía de itinerarios anteriores. Además, hemos seleccionado en el cuadro 5 los itinerarios que, cumpliendo ambos requisitos, superan los $15 \mathrm{~km}$ de longitud, distancia que, para el caso muy habitual de que no tengan carácter circular o de bucle, representa, al menos, $30 \mathrm{~km}$ entre itinerario de ida y de vuelta al final del mismo, y que se entiende como una longitud atractiva para el cicloturista medio.

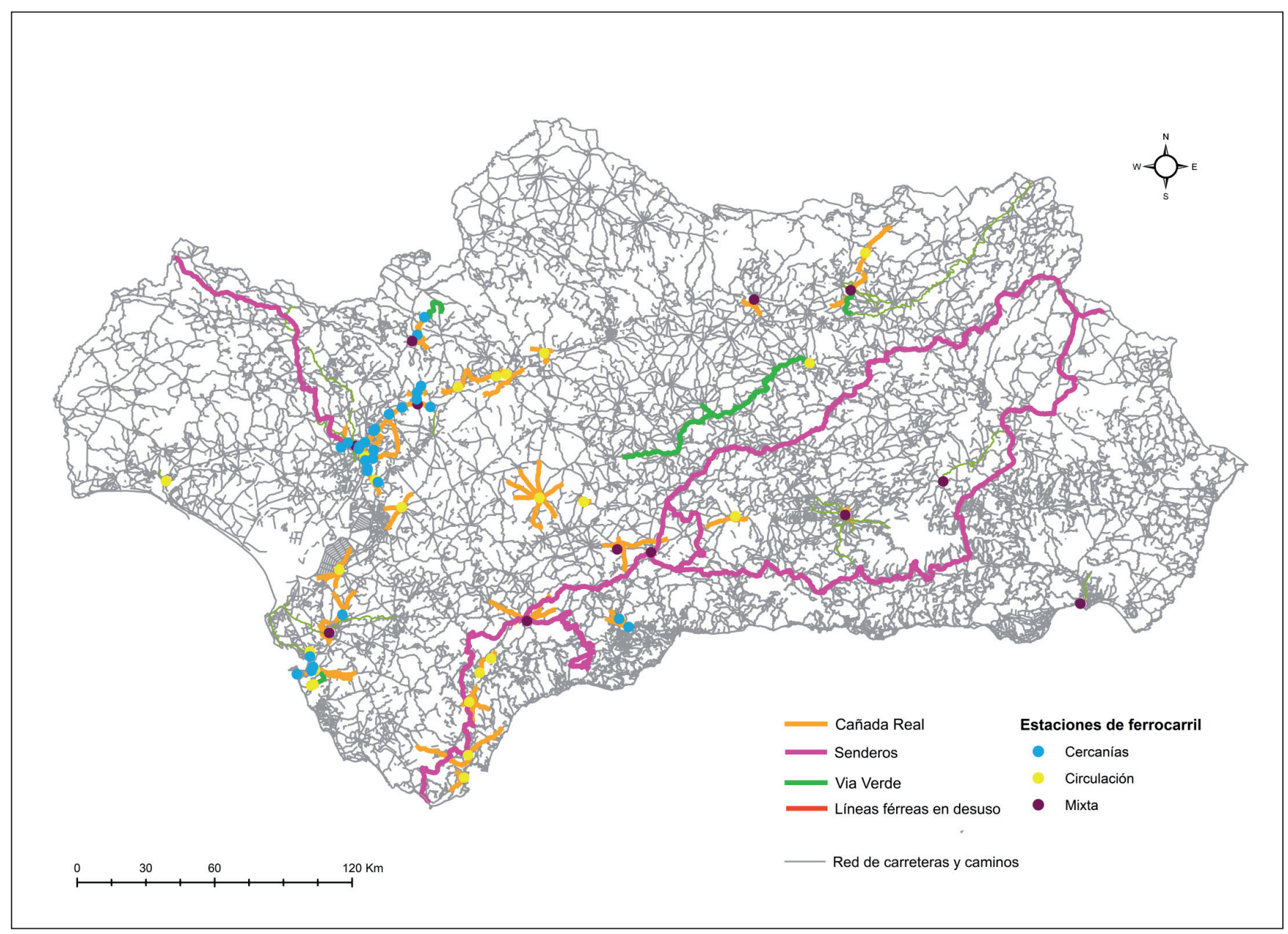

Mapa 2a. Itinerarios a menos de 3 kms. e isócrona de 15’ de estaciones ferroviarias. Fuente: Elaboración propia a partir de datos de DERA y de la Fundación de Ferrocarriles Españoles. 
Cuadro 5. Itinerarios no motorizados de más de $15 \mathrm{~km}$ de longitud a menos de $3 \mathrm{~km}$ y 15 minutos de acceso desde estación ferroviaria en uso.

\begin{tabular}{|c|c|c|c|}
\hline Tipo de itinerario & Nombre del itinerario & Estación/es implicada/as & Longitud en km \\
\hline Sendero & $\begin{array}{l}\text { Sendero Europeo E-4 (Tarifa- } \\
\text { Andorra) GR-7 }\end{array}$ & $\begin{array}{l}\text { Antequera/Jimena de la } \\
\text { Frontera/San Roque-La Línea }\end{array}$ & 981,614 \\
\hline Sendero & Cordel de las Buervas GR-41 & Valencina- Santiponce & 148,821 \\
\hline Ferrocarril en desuso & $\begin{array}{l}\text { Baeza - Utiel. Tramo Baeza- } \\
\text { Bienservida }\end{array}$ & Linares-Baeza & 141,558 \\
\hline Vía Verde & Vía Verde del Aceite & Jaén & 127,357 \\
\hline Sendero & Sierra de las Nieves GR-243 & Ronda & 120,416 \\
\hline Ferrocarril en desuso & Jaén-Campo Real & Jaén & 119,337 \\
\hline Ferrocarril en desuso & Aznalfarache-Cala & Camas & 83,935 \\
\hline Ferrocarril en desuso & $\begin{array}{l}\text { Guadix-Almendricos. Tramo } \\
\text { Guadix-Baza }\end{array}$ & Guadix & 52,331 \\
\hline Ferrocarril en desuso & Linares-Úbeda-Baeza & Linares-Baeza & 41,731 \\
\hline Ferrocarril en desuso & $\begin{array}{l}\text { Puerto de Santa María-Sanlúcar } \\
\text { de Barrameda }\end{array}$ & Puerto de Santa María & 36,014 \\
\hline Ferrocarril en desuso & $\begin{array}{l}\text { Jerez de la Frontera-Arcos de la } \\
\text { Frontera }\end{array}$ & Jerez de la Frontera & 31,076 \\
\hline Cañada Real & $\begin{array}{l}\text { Cañada Real de San Roque a } \\
\text { Medina }\end{array}$ & San Roque-La Línea & 30,881 \\
\hline Ferrocarril en desuso & Camas-Aznalcollar & Valencina-Santiponce & 30,092 \\
\hline Cañada Real & Cañada Real de Sevilla a Málaga & Bobadilla (Antequera) & 29,939 \\
\hline Cañada Real & Cañada Real de Mármol & Lora del Río & 28,544 \\
\hline Cañada Real & $\begin{array}{l}\text { Cañada Real de Navas de San } \\
\text { Juan }\end{array}$ & Vilches & 28,489 \\
\hline Ferrocarril en desuso & Jerez de la Frontera-Bonanza & Jerez de la Frontera & 28,391 \\
\hline Cañada Real & $\begin{array}{l}\text { Cañada Real de Marchena a } \\
\text { Estepa }\end{array}$ & Osuna & 27,188 \\
\hline Cañada Real & Cañada Real de Écija a Teba & Osuna & 26,979 \\
\hline Ferrocarril en desuso & Armilla-Dúrcal & Granada & 26,476 \\
\hline Cañada Real & Cañada Real Guadalimar & Linares-Baeza & 25,971 \\
\hline Cañada Real & Cañada de Sanlúcar a Sevilla & Lebrija & 23,895 \\
\hline Cañada Real & Cañada de Córdoba a Sevilla & Palma del Río & 23,769 \\
\hline Cañada Real & $\begin{array}{l}\text { Cañada Real de Manilva a los } \\
\text { Barrios }\end{array}$ & San Roque-La Línea & 22,593 \\
\hline Ferrocarril en desuso & Granada-Sierra Nevada & Granada & 20,431 \\
\hline Cañada Real & $\begin{array}{l}\text { Cañada Real de Sevilla a } \\
\text { Granada }\end{array}$ & San Francisco de Loja & 20,038 \\
\hline
\end{tabular}




\begin{tabular}{|c|c|c|c|}
\hline Tipo de itinerario & Nombre del itinerario & Estación/es implicada/as & Longitud en km \\
\hline Cañada Real & Cañada Real de Sevilla & Ronda & 19,689 \\
\hline Cañada Real & $\begin{array}{l}\text { Cañada Real del Camino de } \\
\text { Paterna }\end{array}$ & Puerto Real & 18,654 \\
\hline Cañada Real & Cañada Real de Gaucín & Jimena de la Frontera & 18,641 \\
\hline Vía Verde & $\begin{array}{l}\text { Vía Verde de la Sierra Norte de } \\
\text { Sevilla }\end{array}$ & Cazalla-Constantina & 18,281 \\
\hline Cañada Real & Cañada Real de Ronda & Osuna & 17,581 \\
\hline Ferrocarril en desuso & Granada-Fuente Vaqueros & Granada & 17,388 \\
\hline Cañada Real & $\begin{array}{l}\text { Cañada Real de la Rivera del } \\
\text { Huéznar }\end{array}$ & Cazalla-Constantina & 16,507 \\
\hline Cañada Real & $\begin{array}{l}\text { Cañada Real de Leyes o las Ca- } \\
\text { bezas de San Juan y Sevilla }\end{array}$ & La Parra (Jerez de la Frontera) & 16,502 \\
\hline Ferrocarril en desuso & Almería - El Chorrillo & Almería & 16,335 \\
\hline Ferrocarril en desuso & Granada-Pinos Puente & Granada & 16,217 \\
\hline Cañada Real & $\begin{array}{l}\text { Cañada Real de Pero Mingo y de } \\
\text { Palmate }\end{array}$ & $\begin{array}{l}\text { Virgen del Rocío/Padre Pío } \\
\text { Palmete (Sevilla) }\end{array}$ & 16,043 \\
\hline Cañada Real & $\begin{array}{l}\text { Cañada Real de Granada y } \\
\text { Córdoba }\end{array}$ & Ronda & 16,034 \\
\hline Cañada Real & $\begin{array}{l}\text { Cañada Real del Camino de } \\
\text { Medina por Venta Catalana }\end{array}$ & Puerto Real & 15,987 \\
\hline Cañada Real & $\begin{array}{l}\text { Cañada Real de los Palacios a } \\
\text { Carmona }\end{array}$ & Utrera & 15,831 \\
\hline Cañada Real & Cañada Real de Granada & Bobadilla (Antequera) & 15,744 \\
\hline Cañada Real & $\begin{array}{l}\text { Cañada Real de la División de } \\
\text { Términos }\end{array}$ & Brenes & 15,718 \\
\hline Vía Verde & Vía Verde del Guadalimar & Linares-Baeza & 15,313 \\
\hline Cañada Real & Cañada Real de Fuentes & Osuna & 15,148 \\
\hline
\end{tabular}

Fuente: Elaboración propia a partir de un SIG con datos de DERA y FFE.

Esta tabla supone una simplificación a 44 registros de la que se obtenía sin la doble condición, esto es, sólo con el buffer de $3 \mathrm{~km}$ de distancia, y que incorporaba 10 itinerarios más. En el cuadro 6, se reflejan las localidades con estaciones ferroviarias que generan estas 44 rutas, distribuidas según los 6 niveles de jerarquía urbana andaluza establecidos por Gabriel Cano en 2008 (p. 135).

\subsection{Selección de núcleos intermodales e itinerarios no motorizados}

Como consecuencia de todo lo anterior se establecen a continuación los principales núcleos para la implementación de la intermodalidad "tren+bici" que encontramos hoy por hoy en Andalucía, así como una serie de itinerarios no motorizados vinculados a los mismos con sus diferentes características, derivadas del SIG que se ha utilizado como soporte metodológico de esta investigación. Todo ello se refleja en el cuadro siguiente (número 7), y en el posterior mapa 3 de síntesis que ahora también se expone, donde, en principio, 
Cuadro 6. Tipos de localidades andaluzas y denominación de las que generan itinerarios no motorizados de más de $15 \mathrm{~km}$ de longitud a menos de $3 \mathrm{~km}$ y 15 minutos de acceso.

\begin{tabular}{|l|l|}
\hline \multicolumn{1}{|c|}{ Tipología de localidad } & \multicolumn{1}{|c|}{ Nombre de localidades } \\
\hline Capitales de provincia & $\begin{array}{l}\text { Jaén, Granada, Almería y Sevilla (por Virgen del Rocío/ } \\
\text { Padre Pío Palmete) }\end{array}$ \\
\hline Centros comarcales & $\begin{array}{l}\text { Antequera (por Bobadilla), Linares (por Linares-Baeza), } \\
\text { Ronda, Guadix, Jerez de la Frontera (incluye estación } \\
\text { de La Parra), Lora del Río, Palma del Río, Loja (por } \\
\text { la estación de San Francisco), Cazalla (por Cazalla- } \\
\text { Constantina) y Utrera. }\end{array}$ \\
\hline Núcleos en aglomeraciones urbanas & $\begin{array}{l}\text { San Roque (por San Roque-La Línea), Camas, Puerto de } \\
\text { Santa María, Puerto Real y Brenes. }\end{array}$ \\
\hline Localidades en áreas polinucleares & Osuna y Lebrija. \\
\hline Otros centros & Jimena de la Frontera y Las Cabezas de San Juan. \\
\hline Resto de cabeceras municipales & Valencina (por Valencina-Santiponce) y Vilches. \\
\hline
\end{tabular}

Fuente: Elaboración propia a partir de tipología de ciudades andaluzas de G. Cano (2008; p. 135) y estaciones ferroviarias del cuadro 5.

se atiende sólo a itinerarios que, en su conjunto, superen los $20 \mathrm{~km}$ y que partan de las proximidades (con distancia nunca superior a los $3 \mathrm{~km}$ ) de las estaciones correspondientes a localidades adscritas a las categorías de capitales de provincia y centros comarcales del anterior cuadro 6.

No obstante, de la revisión de los 10 itinerarios que sólo cumplían la condición de iniciarse a menos de $3 \mathrm{~km}$ de la estación ferroviaria pero que no se encuentran a menos de 15 minutos de acceso desde la misma, observamos 2 casos excepcionales y significativos, como son los que corresponden a Marchena, donde la Vía Verde de la Campiña se inicia a sólo 364 m de la misma; y la estación de cercanías de San Julián (en Málaga), a 106 m del ferrocarril en desuso Málaga-Coín. El que no aparezcan en la isócrona seleccionada lo consideramos una anomalía consecuencia de la capa fuente utilizada, según comentaremos más adelante, lo que nos ha llevado a considerar también estas dos estaciones, a menos de $500 \mathrm{~m}$ del inicio de sus itinerarios, en la relación de los que aquí se proponen como prioritarios a potenciar en Andalucía.

Como vemos en el cuadro 7 los itinerarios seleccionados presentan una longitud, ordenada aquí de mayor a menor, que oscila entre los 127,36 km de la actual Vía Verde del Aceite, en las provincias de Córdoba y Jaén, y los poco más de $20 \mathrm{~km}$ de la Cañada Real de Granada a Sevilla en las proximidades de la estación de San Francisco, en Loja (Granada). Sólo las provincias de Huelva y Almería, los extremos longitudinales del territorio andaluz, no cuentan con representación en esta selección inicial de itinerarios no motorizados más atractivos para la promoción del cicloturismo en Andalucía. En el caso onubense la amplia oferta de ferrocarriles mineros abandonados (Romero, E. M., 2007) no genera sin embargo ninguno ajustado a los criterios en este estudio; y en el caso de Almería entendemos que es su menguado desarrollo ferroviario (Gavira, A. y Ventura, J., 2017), el que determina que no se establezca ningún itinerario de interés en este primer momento, aunque existen algunas opciones de menor calado.

Ahora bien, la ejecución de estos posibles itinerarios, para el caso de los que todavía no están en activo, dependerá, finalmente, y con independencia de los imprescindibles recursos económicos, de si cumplen una serie de requisitos para la realización de actividades cicloturísticas y recreativas, como son parámetros de pendientes, tipología del terreno que atraviesan y que enlacen lugares de interés natural y cultural, fundamentalmente, lo que implica estudios posteriores de mayor detalle. 
Cuadro 7. Selección de estaciones intermodales “tren+bici” y principales itinerarios no motorizados asociados propuestos para Andalucía.

\begin{tabular}{|c|c|c|c|c|}
\hline $\begin{array}{l}\text { Estación intermodal } \\
\text { "tren+bici" }\end{array}$ & Itinerario no motorizado & $\mathrm{N}^{\circ}$. & $\begin{array}{l}\text { Distancia al Inicio en línea recta } \\
\text { desde estación ferroviaria }\end{array}$ & Longitud \\
\hline Jaén & $\begin{array}{l}\text { Vía Verde del Aceite. Procede de la } \\
\text { fusión de las antiguas vías verdes de } \\
\text { la Subbética, Guadajoz-Subbética y } \\
\text { del Aceite }\end{array}$ & 1 & $1,89 \mathrm{~km}$ & $127,36 \mathrm{~km}$ \\
\hline Marchena & $\begin{array}{l}\text { Vía Verde de la Campiña. Procede de } \\
\text { la fusión de las antiguas vías verdes } \\
\text { de la Campiña sevillana y Campiña } \\
\text { cordobesa }\end{array}$ & 2 & $0,37 \mathrm{~km}$ & $91,92 \mathrm{~km}$ \\
\hline Lora del Río & $\begin{array}{l}\text { Cañada Real de Mármol y Cañada } \\
\text { Real Soriana o de Castilla }\end{array}$ & 3 & $\begin{array}{l}\text { Discurre por la propia estación } \\
\text { de Lora del Río }\end{array}$ & $72,52 \mathrm{~km}$ \\
\hline Guadix & $\begin{array}{l}\text { Línea de ferrocarril en desuso } \\
\text { Guadix-Baza y Vía Verde de la } \\
\text { Sierra de Baza. Tramo inicial del } \\
\text { ferrocarril en desuso entre Guadix y } \\
\text { Almendricos (Murcia) }\end{array}$ & 4 & $\begin{array}{l}\text { Parte de la propia estación } \\
\text { ferroviaria }\end{array}$ & $\begin{array}{l}57 \mathrm{~km} \\
\text { aprox. }\end{array}$ \\
\hline Ronda & $\begin{array}{l}\text { Cañada Real de Sevilla y Cañada Real } \\
\text { de Granada y Córdoba }\end{array}$ & 5 & $\begin{array}{l}\text { Discurre por la propia estación } \\
\text { de Ronda }\end{array}$ & $35,72 \mathrm{~km}$ \\
\hline Cazalla-Constantina & $\begin{array}{l}\text { Vía Verde de la Sierra Norte y Cañada } \\
\text { Real de la Rivera del Huéznar }\end{array}$ & 6 & $0,20 \mathrm{~km}$ & $\begin{array}{l}33 \mathrm{~km} \\
\text { aprox. }\end{array}$ \\
\hline Jerez de la Frontera & $\begin{array}{l}\text { Tramo inicial de ferrocarril } \\
\text { desmantelado, hasta Arcos de la } \\
\text { Frontera }\end{array}$ & 7 & $2,16 \mathrm{~km}$ & $31 \mathrm{~km}$ \\
\hline Granada & $\begin{array}{l}\text { Cañada Real de Trashumancia y } \\
\text { línea de ferrocarril en desuso hasta } \\
\text { Armilla-Dúrcal }\end{array}$ & 8 & $0,40 \mathrm{~km}$ & $\begin{array}{l}30 \mathrm{~km} \\
\text { aprox. }\end{array}$ \\
\hline Bobadilla (Antequera) & Cañada Real de Sevilla a Málaga & 9 & $2,77 \mathrm{~km}$ & $29,94 \mathrm{~km}$ \\
\hline San Julián (Málaga) & $\begin{array}{l}\text { Línea de ferrocarril en desuso hasta } \\
\text { Coín }\end{array}$ & 10 & $0,10 \mathrm{~km}$ & $29,77 \mathrm{~km}$ \\
\hline Jerez de la Frontera & $\begin{array}{l}\text { Cañada del Pino Solete y línea de } \\
\text { ferrocarril en desuso Jerez de la } \\
\text { Frontera-Bonanza }\end{array}$ & 11 & $\begin{array}{l}\text { Parte de la propia estación de } \\
\text { Jerez de la Frontera }\end{array}$ & $\begin{array}{l}29 \mathrm{~km} \\
\text { aprox. }\end{array}$ \\
\hline $\begin{array}{l}\text { Virgen del Rocío/Padre } \\
\text { Pío Palmete (Sevilla) }\end{array}$ & $\begin{array}{l}\text { Cañada Real de Pero Mingo y } \\
\text { Palmete y Cañada Real de la Armada }\end{array}$ & 12 & $\begin{array}{l}0,28 \text { km desde la estación Padre } \\
\text { Pío Palmete }\end{array}$ & $27,81 \mathrm{~km}$ \\
\hline Linares-Baeza & $\begin{array}{l}\text { Vías verdes de Linares y de } \\
\text { Guadalimar unidas por línea de } \\
\text { ferrocarril en desuso }\end{array}$ & 13 & $0,20 \mathrm{~km}$ & $24,20 \mathrm{~km}$ \\
\hline Palma del Río & Cañada Real de Córdoba a Sevilla & 14 & $2,37 \mathrm{~km}$ & $23,77 \mathrm{~km}$ \\
\hline Granada & $\begin{array}{l}\text { Cañada Real de Trashumancia y línea } \\
\text { de ferrocarril en desuso a Sierra } \\
\text { Nevada }\end{array}$ & 15 & $0,40 \mathrm{~km}$ & $\begin{array}{l}23,50 \mathrm{~km} \\
\text { aprox. }\end{array}$ \\
\hline San Francisco de Loja & Cañada Real de Sevilla a Granada & 16 & $2,08 \mathrm{~km}$ & $20,03 \mathrm{~km}$ \\
\hline
\end{tabular}

Fuente: Elaboración propia a partir del SIG diseñado para el estudio realizado. 


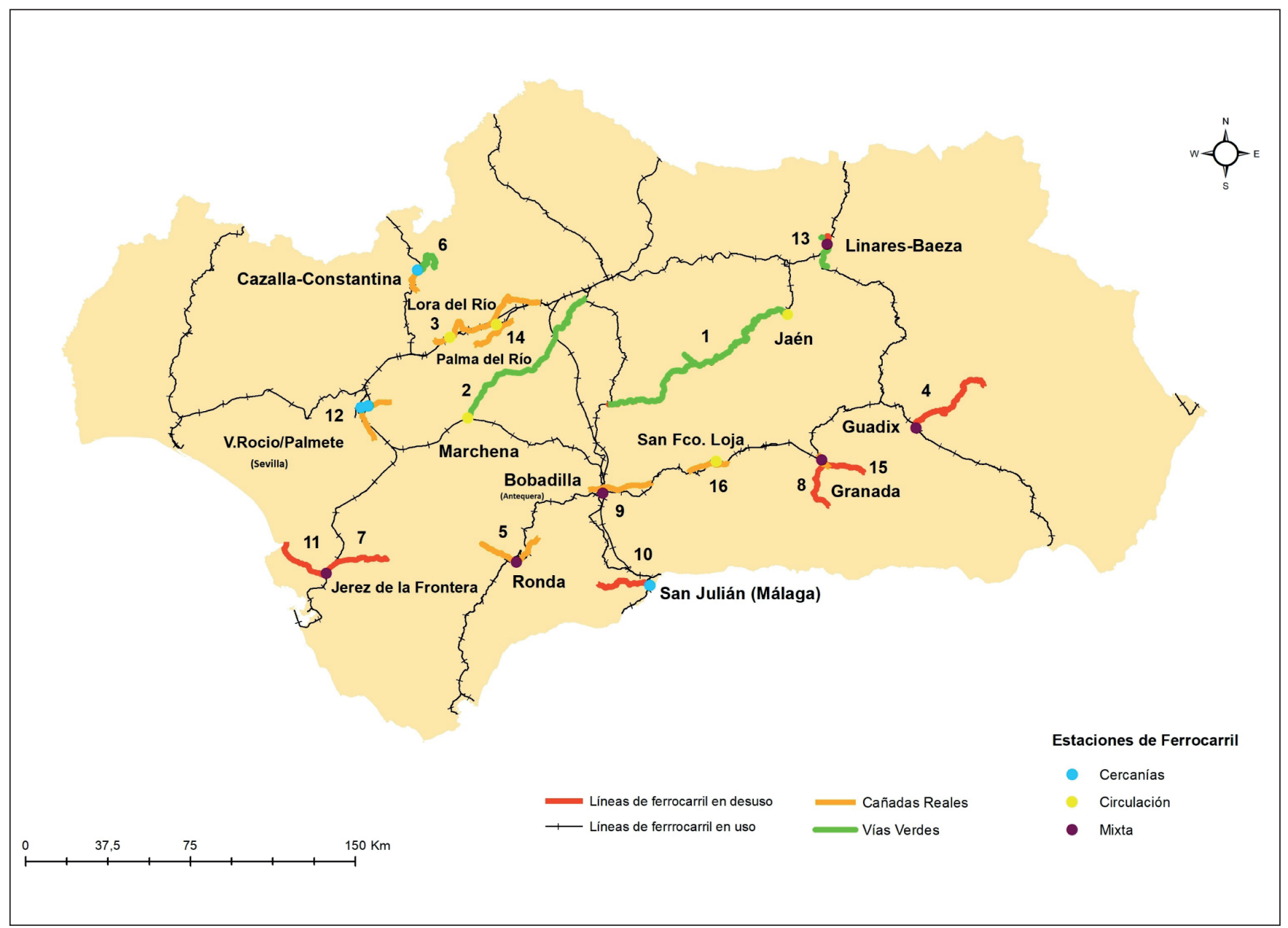

Mapa 3. Estaciones intermodales "tren+bici” y principales itinerarios asociados.

Fuente: Elaboración propia a partir de datos de DERA y de la Fundación de Ferrocarriles Españoles.

\section{DEBATE DE SITUACIÓN Y DISCUSIÓN TÉCNICA}

De este estudio cabe deducir que el cicloturismo se encuentra en estos momentos en España y Andalucía en una fase de despegue, disponiendo, por tanto, de un gran potencial para tener éxito como motor dinamizador de espacios rurales, donde se combinan diferentes características, desde el respeto por la naturaleza, aspectos beneficiosos para la salud y derramas económicas que se aportan a lo largo de estos itinerarios (Fernández, F., 2015; Eizaguirre et al., 2016; y Ventura, J. y Gavira, A., 2016).

También es cierto que nos encontramos ante una disponibilidad reducida para acceder en tren a estos itinerarios no motorizados con bicicletas, ya que la normativa de acceso al transporte ferroviario con ellas es, en España, más restrictiva que en otros países de nuestro entorno, donde existe mayor número de trenes a los que se puede acceder con bicicletas y que presentan además una frecuencia de paso más elevada. Por tanto, el binomio "tren+bici" es, en esos espacios, una forma muy utilizada, fácil y cómoda de llegar a estos itinerarios no motorizados, algo que no sucede aún en España.

No obstante, la actual normativa de RENFE sobre transporte de bicicletas, que data de 2016 (http://www. renfe.com/viajeros/info/bicicletas.html), resulta más favorable para el usuario, al ampliar esta posibilidad a todos sus trenes, aunque con restricciones en los de Larga Distancia, AVE y Avant (https://conalforjas.com/ transportar-bicicleta-tren/), donde éstas tendrán que ir desmontadas o plegadas y enfundadas, sin sobrepasar unas dimensiones de $120 \times 90 \times 40 \mathrm{~cm}$. Este hecho, desde la plataforma Pedalibre (https://pedalibre. org/2016/04/04/la-bicicleta-en-renfe-larga-distancia/), se considera, en general, positivo para el desarrollo de la actividad cicloturística y un avance en la normativa, si bien indican que no ha ido acompañado de me- 
joras en el material para poder transportar las bicicletas dentro de los vagones, condicionando, por tanto, el desplazamiento en grupo, y quedando en manos de la autoridad (interventor) la determinación de las posibles molestias ocasionadas por las bicicletas, pudiéndose en ese caso denegar el viajar en tren con las mismas.

Con respecto a Media Distancia y Cercanías no resulta necesario desmontarlas ni enfundarlas, aunque para trayectos superiores a $100 \mathrm{~km}$ hay que abonar $3 €$ (gratuito para distancia inferior). En los trenes de Cercanías, si van muy completos, el interventor puede denegarnos el acceso con bicicleta, de forma que, en ese supuesto, sólo cabe optar por esperar al siguiente convoy o bien solicitar la devolución del billete. En todo caso, las bicicletas deben de ir en el espacio destinado a las mismas, muy poco habitual, por lo que, de no existir tal área, se situarán en los ámbitos de acceso a los vagones, con la consiguiente incomodidad que ello supone.

Otra de las diferencias significativas que existen entre nuestro país con respecto a otros europeos y del resto del mundo, es el hecho de denominar "vías verdes" (greenways en inglés), sólo a los antiguos trazados ferroviarios que se encuentren en desuso y que ya han sido rehabilitados y acondicionados (de hecho se trata de una marca debidamente registrada por la Fundación de los Ferrocarriles Españoles); mientras que en otros entornos se denominan "greenways", además de a antiguos tramos de ferrocarril en desuso, a aquellos itinerarios no motorizados procedentes de vías pecuarias o caminos rurales,..., siempre que estén debidamente acondicionados (Aycart, C., 2001; Serra, M., 2016). De hecho, en España, y para buscar un punto de encuentro con este planteamiento generalizado en Europa, se ha impulsado el programa de "Caminos Naturales", donde ya no hay condicionante previo en cuanto al origen del itinerario no motorizado, si bien un porcentaje elevados de ellos, como por ejemplo sucede en Andalucía, coincide con las anteriormente referidas "vías verdes" (https://www.mapa.gob.es/es/desarrollo-rural/temas/caminos-naturales/).

Por último hay que poner sobre la mesa de discusión un problema de carácter técnico con el que nos hemos encontrado en este estudio. Se trata de la aparente falta de conectividad entre estaciones ferroviarias en uso e itinerarios que comienzan a menos de $500 \mathrm{~m}$ de las mismas, como son los casos, ya mencionados, que afectan a las estaciones de Marchena (en la provincia de Sevilla) y San Julián (Málaga), donde, como se aprecia en el mapa 4, y ante la falta de una red tupida de conexiones, la isócrona de 15 minutos se establece sobre el viario más próximo a la estación aunque sea por una diferencia ínfima de distancia, lo que puede conllevar a que itinerarios importantes, como sería el caso de una vía verde consolidada (La Campiña), no esté dentro de la misma, y aparentemente no cumpla la doble condición establecida (cercanía y accesibilidad) para formar parte de los itinerarios más destacados.

Entendemos que todo ello constituye, por tanto, una disfunción a tener en cuenta en cualquier análisis de redes, muy dependiente de la calidad de la capa fuente, que, aunque siempre mejorable procurando disponer de otras de mayor detalle, requiere en cualquier caso de una revisión minuciosa que corrija este tipo de circunstancias, tal como aquí se ha hecho para establecer la relación final de itinerarios principales de cara a la promoción del cicloturismo en Andalucía.

\section{CONCLUSIONES}

Las actividades cicloturísticas están teniendo, como se ha visto, un fuerte auge como motor económico, por lo que países como Francia, Alemania, Reino Unido, en Europa, y otros como EEUU o Australia han incrementado su potencial, contando, algunos de ellos, con una larga trayectoria y, por lo tanto, al tratarse de destinos maduros, disponen de infraestructuras modernas y servicios asociados a estos itinerarios y al uso de la bicicleta, con ofertas de información muy detalladas, encontrándose bien señalizados, lo que los hace seguros y muy atractivos.

Estos casos de éxito en Europa, y las rutas cicloturísticas que se están desarrollando en otros continentes, ponen de manifiesto la importancia de determinar los nodos intermodales que combinen el transporte público y colectivo, como es el de carácter ferroviario, y la accesibilidad a los itinerarios no motorizados, sobre todo en una región, como Andalucía, con importantes flujos turísticos, lo que diversificaría su oferta y 


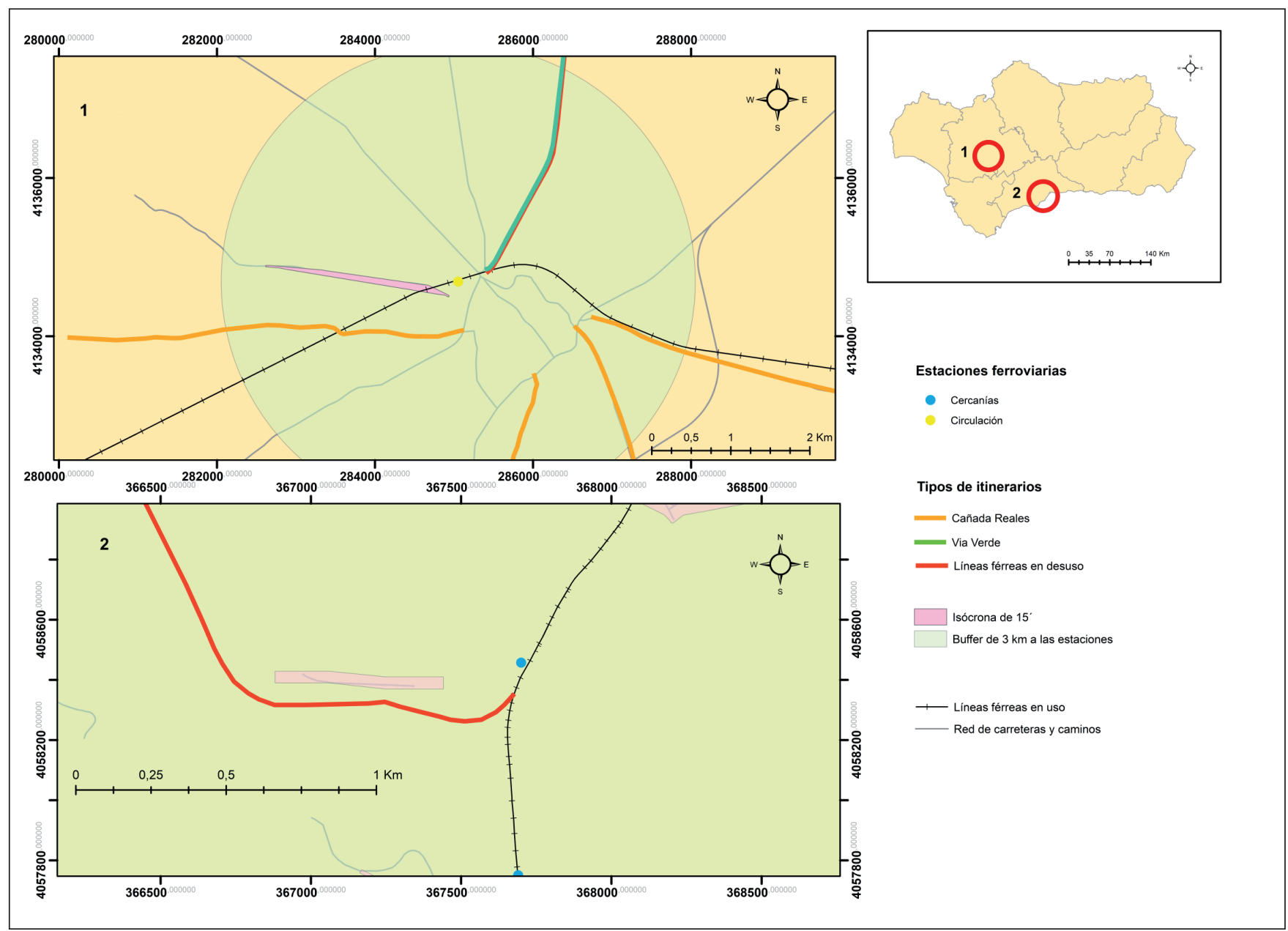

Mapa 4. 1: Vista ampliada del caso de la estación ferroviaria de Marchena (Sevilla). 2: Vista Vista ampliada del caso de la estación ferroviaria de San Julián (Málaga).

Fuente: Elaboración propia a partir de datos de DERA y de la Fundación de Ferrocarriles Españoles.

deslocalizaría la presión turística de ciertas áreas para extenderla a través de su territorio, poniendo en valor el patrimonio natural, cultural, arquitectónico y etnográfico del interior de la Comunidad.

Estos núcleos intermodales deben cumplir con una serie de requisitos para que tengan éxito, y para ello será necesario que sean accesibles a todos, con infraestructuras y servicios adecuados para los usuarios de la bicicleta. En este sentido las asociaciones ciclistas han tenido un papel fundamental en la conservación y en el trazado de nuevas rutas para el desarrollo del senderismo y del cicloturismo y, por lo tanto, para la implantación de un nuevo modelo turístico sostenible y respetuoso con el medioambiente.

En España, desde la Fundación de los Ferrocarriles Españoles (FFE), con su Programa Vías Verdes, existente desde 1993, cuando se inventariaron más de 7.600 km que ya no tenían servicio de trenes, o que incluso nunca llegaron a tenerlo por quedar inconclusas las obras de construcción, se han reconvertido más de $2.700 \mathrm{~km}$ de estas antiguas líneas férreas en itinerarios no motorizados para la actividad cicloturística y senderista, fundamentalmente. Sobre un total de 120 rutas, 27 de ellas se sitúan en la Comunidad andaluza, con más de $580 \mathrm{~km}$ operativos, y una proporción superior a su peso en superficie dentro del conjunto español.

Para Andalucía la cartografía resultante del análisis de las potencialidades intermodales existentes entre líneas férreas e itinerarios no motorizados ha servido para realizar diferentes diagnósticos. En primer lugar, se ha detectado cómo, a sólo $3 \mathrm{~km}$ de estaciones ferroviarias en funcionamiento, de los tipos cercanías, circulación y mixta, comienzan una serie de rutas de distinto tipo (cañadas reales, senderos, vías verdes y líneas de ferrocarriles en desuso sin acondicionar) que alcanzan más de $3.400 \mathrm{~km}$, con un reparto proporcional que oscila entre el $36,74 \%$ que representan los senderos al $28,63 \%$ de las líneas férreas abandonadas. 
De estos trazados, 54 de ellos superan los $15 \mathrm{~km}$ de longitud. Pero para medir su operatividad real se ha añadido al estudio un segundo condicionante, como es el que se acceda a ellos en un tiempo inferior a los 15 minutos, a partir de la red de carreteras (excluidas las de doble trazado) y caminos facilitada por el repertorio DERA del IECA, con una malla de $57.717,82 \mathrm{~km}$. En ese caso los itinerarios que superan los $15 \mathrm{~km}$ de longitud son ya sólo 44.

Con estos planteamientos, y elevando el mínimo de recorrido a los $20 \mathrm{~km}$, pero con la posibilidad de sumar itinerarios de diferente tipología que presenten contigüidad evidente en el Sistema de Información Geográfica elaborado al efecto, se han seleccionado los 16 itinerarios más favorables para promover la intermodalidad "tren+bici" en Andalucía, algunos ya en servicio, como sucede en las denominadas vías verdes (del Aceite, de la Campiña, de la Sierra Norte...).

En cualquier caso, debemos señalar que con los datos derivados de este trabajo queda patente la necesidad de colaboración entre los diferentes agentes locales, administraciones a diferentes escalas, asociaciones de ciudadanos, fundaciones públicas y empresas privadas para el mantenimiento (conservación de los trazados ya existentes) y para la creación de nuevos trayectos.

En definitiva, la aportación de esta investigación radica, pensamos, en la realización un análisis que ha venido a combinar diferentes variables por medio de un SIG, donde se han empleado ítems de distinto tipo junto con un soporte cartográfico que ha servido como modelo de interrelación de éstos para generar una mapificación y una tabulación que ayude a la toma de decisiones por medio de un diagnóstico de situación inicial.

El caso de Andalucía presenta, además, un gran potencial para ser un referente de la actividad cicloturística, pero para ello será necesario, por un lado, que la normativa del transporte de bicicletas sea todavía más flexible; $y$, por otro lado, que las administraciones públicas y las entidades privadas aúnen esfuerzos para poner en marcha proyectos de nuevos itinerarios que faciliten las pernoctaciones con servicios adaptados a las necesidades de los usuarios y la bicicleta.

De este modo, para que estos recorridos y sus actividades cicloturísticas inherentes puedan seguir adelante, resulta imprescindible que exista un mantenimiento efectivo de los ya disponibles y de las nuevas rutas que se diseñen; y que los diferentes actores que intervienen en este sector participen en sus diferentes fases (financiación, diseño y ejecución), así como en el fomento del uso de la bicicleta, con proyectos de movilidad sostenible y turismo en el territorio, existiendo, por consiguiente, una coordinación real y eficiente, algo que, por desgracia, no siempre sucede.

\section{REFERENCIAS}

Aycart-Luengo, C. (2001). Vías Verdes, Reutilización de Ferrocarriles en desuso para la Movilidad Sostenible, Ocio y Turismo. Informes de la construcción, 53 (475), 17-32. doi: https://doi.org/10.3989/ic.2001.v53.i475.653

Aycart-Luengo, C. (2006). El programa español de Vías Verdes. Revista del Colegio de Ingenieros Técnicos de Obras Públicas, $369,22-31$.

Camagni, R. y Capello, R. (2013). Regional Competitiveness and Territorial Capital: A Conceptual Approach and Empirical Evidence from the European Union. Regional Studies, 47 (9), 1383-1402. doi: https://doi.org/10.1080/00343404.201 2.681640

Caminos Naturales. Recuperado de https://www.mapa.gob.es/es/desarrollo-rural/temas/caminos-naturales/ Último acceso: 15/5/2019.

Cano-García, G. (2008). Clasificaciones Urbanas en Andalucía. Las Ciudades Medias, Revista de Estudios Andaluces, 27, 115-153. doi: https://doi.org/10.12795/rea.2008.i27.05

Cebrián-Abellán, F. (2011). Los ferrocarriles olvidados. Reconversión y reinvención como instrumentos de revitalización recreativa y turística: el Baeza-Utiel a su paso por la provincia de Albacete. Cuadernos de Turismo, 27, 205-225.

Conalforjas. Recuperado de https://conalforjas.com/transportar-bicicleta-tren/ Último acceso: 24/6/2019.

Consejería de Fomento y Vivienda (2014). Plan Andaluz de la Bicicleta. PAB 2014-2020. Junta de Andalucía. Recuperado de http://www.aopandalucia.es/planandaluzdelabicicleta/ Último acceso: 10/5/2019. 
Consejería de Turismo y Deporte (2016). Plan General de Turismo Sostenible de Andalucía Horizonte 2020. Junta de Andalucía. Recuperado de http://www.juntadeandalucia.es/turismoydeporte/opencms/areas/turismo/opciones-de-planificacion-turistica/planificacion-turistica-estrategica/plan-general-del-turismo-sostenible-de-andalucia-horizonte-2020/ Último acceso: 10/5/2019.

Eizaguirre-Iribar, A., Igiñiz, L E. y Hernández-Minguillón, R. J. (2016). A multilevel approach of non-motorised accessibility in disused railway systems: The case-study of the Vasco-Navarro railway. Journal of transport geography 57, 35-43. doi: 10.1016/j.jtrangeo.2016.09.009

Escalona-Orcao, A. I. y Díez-Cornago, C. (2005). Retos y problemas de la accesibilidad a los servicios en zonas despobladas: un caso en la provincia de Teruel (España). Scripta Nova: Revista Electrónica de Geografía y Ciencias Sociales, IX, 188.

EuroVelo. Recuperado de http://www.eurovelo.com/en Último acceso: 15/5/2019.

Faulks, P., Ritchie, B. y Fluker, M. (2006). Cycle Tourism in Australia: An investigation into its size and scope. Sustainable Tourism CRC. Recuperado de https://www.back-in-business-physiotherapy.com/images/files/CycleTourismReport.pdf Último acceso: 23/5/2019.

Fernández-Latorre, F. M. (2015). Flujos turísticos, capital territorial y uso de la bicicleta. Andalucía como modelo de destino emergente en cicloturismo. Revista de Estudios Andaluces, 32, 76-107. doi: http://dx.doi.org/10.12795/rea.2015. i32.04

Freire-Valderrama, J. (2018). La bicicleta en Andalucía: Una herramienta para el necesario cambio de modelo económico, social y ambiental. Andalucía Geográfica, 11.

Movilidad Sostenible en Andalucía, 45-55. Recuperado de https://geografosdeandalucia.org/index.php/colegio/andalucia-geografica Último acceso: 10/5/2019.

Gavira-Narváez, Antonio y Ventura-Fernández, J. (2013). Procesos actuales y perspectivas para el transporte ferroviario de viajeros en Andalucía. Investigaciones Geográficas, 59, 25-41. doi: https://doi.org/10.14198/INGEO2013.59.02

Gavira-Narváez, A. y Ventura-Fernández, J. (2017). Evolución y panorama actual de la red ferroviaria en Andalucía. Cuadernos Geográficos, 56 (2), 283-305.

Insall, P. (2004). La red nacional británica de rutas ciclistas: marco para un enfoque integrado de la gestión de la movilidad. Ingeniería y territorio, 69, 38-43.

Instituto de Estadística y Cartografía de Andalucía. Datos Espaciales de Referencia de Andalucía (DERA). Consejería de Economía, Conocimiento, Empresas y Universidad de la Junta de Andalucía. Recuperado de https://www.juntadeandalucia.es/institutodeestadisticaycartografia/DERA/ Último acceso: 10/5/2019.

Luque-Valle, P. (2012). Análisis del modelo de uso-visita de los deportistas-turistas de las vías verdes andaluzas. Editorial Universidad de Granada. Recuperado de http://hdl.handle.net/10481/20995 Último acceso: 22/5/2019.

Martín-Cejas, F. R. y Martínez-Hernández, P. (2017). La movilidad turística en la Isla de Lanzarote: el diseño de una ruta para un autobús turístico. International Journal of Scientific Management and Tourism, 3 (3), 459-477.

Mató, Emili y Troyano, Xandra (2014). Impacto Económico del cicloturismo en Europa. Síntesis de los principales estudios realizados. Agencia de Obra Pública de la Junta de Andalucía de la Consejería de Fomento y Vivienda de la Junta de Andalucía. Recuperado de https://www.viasverdes.com/prensa/documentos/interes/Informe_Cicloturismo_2014. pdf último acceso: 10/5/2019.

Mercat, Nicolas (2018). El caso de Francia. Ponencias de la Conferencia 25 Años de Vías Verdes, celebrada en Sevilla los días 22 y 23 de octubre de 2018. Recuperado de http://www.viasverdes.com/pdf/Ponencias25VV/S202_Mercat_Inddigo.pdf Último acceso: 10/5/2019.

Pedalibre. Recuperado de https://pedalibre.org/2016/04/04/la-bicicleta-en-renfe-larga-distancia/ Último acceso: 24/6/2019.

Pedrosa, A., Albuquerque, H. y Breda, Z. (2019). Development of Bike Touring Routes in the Aveiro Region Using Geographical Information Systems. 2nd International Conference on Tourism Research, 216-225.

Pucher, J., Buehler, R., Sgm, F. (2008). Making Cycling Irresistible: Lessons from The Netherlands, Denmark and Germany. Transport Reviews, 28 (4), 495-5281464. doi: 10.1080/01441640701806612.

Rails to trails conservancy. Recuperado de https://www.railstotrails.org/ Último acceso: 11/6/2019.

Rebollo-Rico, S. (2003). El turismo deportivo y la formación en ciencias del deporte. Habilidad motriz: Revista de ciencias de la actividad física y del deporte, 21, 11-14. 
Renfe. Recuperado de http://www.renfe.com/viajeros/info/bicicletas.html Último acceso: 24/6/2019.

Romero, E. M. (director, 2008). Los ferrocarriles en la provincia de Huelva. Un recorrido por el pasado. Huelva, Universidad de Huelva.

Rincón-Millán, J. (2013). La antigua línea de ferrocarril Jerez-Almargen: su reconversión en camino natural. Universidad de Sevilla. Recuperado de http://hdl.handle.net/11441/47570

Serra-Serra, M. (2016). El cicloturismo y las vías verdes como ejemplo de turismo sostenible. Revista CIDOB d'Afers Internacionals, 187-209. Recuperado de https://www.jstor.org/stable/pdf/24897287

Stehlíková, J. y Řezník, T. (2018). An accessible Brno city centre for people with impaired mobility, Journal of Maps, 14 (1), 81-87. doi: 10.1080/17445647.2018.1526716

Sustrans. Recuperado de http://www.sustrans.org.uk/ Último acceso: 10/6/2019.

Ventura-Fernández, J. y Gavira-Narváez, A. (2016). Las vías verdes como dinamizadoras del desarrollo territorial sostenible en Andalucía. Recuperado de http://abcblogs.abc.es/riqueza-regiones/2016/02/22/las-vias-verdes-como-dinamizadoras-del-desarrollo-territorial-sostenible-en-andalucia/ Último acceso: 23/5/2019.

Ventura-Fernández, J., González-Relaño, R. y Gavira-Narváez, A. (2017). Accessibility of rail trails in Huelva, Andalusia (Spain), Journal of Maps, 13 (1), 62-66. doi: 10.1080/17445647.2017.1323033

Vías Verdes. Recuperado de https://www.viasverdes.com/ Último acceso: 15/5/2019.

Vías Verdes de Andalucía. Recuperado de www.viasverdesandalucia.es Último acceso: 24/5/2019.

Vías Verdes y Red Natura 2000. Recuperado de www.viasverdesyrednatura2000.com Último acceso: 22/5/2019.

Weston, R. et al. (2012). The European Cycle Route Network EuroVelo. Recuperado de http://www.europarl.europa.eu/RegData/etudes/etudes/join/2012/474569/IPOL-TRAN_ET(2012)474569_EN.pdf Último acceso: 23/5/2019. 